\title{
Low dose colestipol in adolescents with familial hypercholesterolaemia
}

Lipid Clinic, Medical Department A, National Hospital, Oslo, Norway S Tonstad M Sivertsen L Ose

Department of Paediatrics, Haukeland Hospital, Bergen, Norway L Aksnes

Correspondence to: Dr Serena Tonstad, Lipid Clinic, National Hospital N-0027 Oslo, Norway.

Accepted 17 October 1995

\author{
S Tonstad, M Sivertsen, L Aksnes, L Ose
}

\begin{abstract}
The effects of orange flavoured colestipol granules, $10 \mathrm{~g} / \mathrm{day}$, in 37 boys and 29 girls aged 10-16 years with familial hypercholesterolaemia were examined first in an eight week double blind, placebo controlled protocol, then in open treatment for 44-52 weeks. All patients were on a low fat diet. Low density lipoprotein cholesterol levels were reduced by $19.5 \%$ by colestipol $v 1.0 \%$ by placebo. Levels of serum folate, vitamin $E$, and carotenoids were reduced in the colestipol group, but not the vitamin $\mathrm{E} /$ cholesterol and carotenoid/cholesterol ratios or serum concentrations of vitamins $A$ and D. After one year of colestipol, two thirds of the participants remained in the study, of whom half took $\geqslant 80 \%$ of the prescribed dose. Those who took $\geqslant 80 \%$ of the dose had a greater decrease in serum 25hydroxyvitamin D levels than those who took $<80 \%$. No adverse effects on weight gain or linear growth velocity were observed. Although low dose colestipol effectively reduces low density lipoprotein cholesterol levels, only a minority of adolescents adhered to the new formulation for one year. Folate and possibly vitamin $D$ supplementation is recommended. (Arch Dis Child 1996; 74: 157-160)
\end{abstract}

Keywords: familial hypercholesterolaemia, colestipol, vitamins.

Treatment for raised low density lipoprotein (LDL) cholesterol levels is recommended for children with familial hypercholesterolaemia, first with diet, and then with drugs as well in some cases. ${ }^{12}$ No HMG-CoA reductase inhibitors have been approved for use before adulthood. Niacin is effective, but causes side effects. ${ }^{3}$ Bile acid binding resins, colestipol, and cholestyramine remain the drugs of choice. Current guidelines recommend that treatment with resins begin after age 10 years, if dietary treatment fails to lower LDL cholesterol levels sufficiently. ${ }^{1}$

Children may be unwilling to take resins for long periods of time, particularly when the drug is started during adolescence. ${ }^{45}$ The main reason for poor compliance is unpalatability, as gastrointestinal side effects are less common than among adults. ${ }^{5} 6$ Recently, colestipol became available as orange flavoured granules with a smaller particle diameter than the previous formulation. We examined the efficacy of the new granules in adolescents with familial hypercholesterolaemia. Changes in nutritional indices and the incidence of side effects were the main variables studied.

\section{Methods}

All adolescents age 10 to 16 years previously referred to the clinic, with two or more total cholesterol concentrations of $\geqslant 6.2 \mathrm{mmol} / \mathrm{l}$ and triglyceride $<3.0 \mathrm{mmol} / \mathrm{l}$, were asked to join. Sixty six of seventy four agreed ( 37 boys and 29 girls). The diagnosis of familial hypercholesterolaemia was based on total cholesterol concentrations of $\geqslant 7.8 \mathrm{mmol} / \mathrm{l}$ and tendon xanthoma in one or both parents and in relatives in a manner compatible with autosomal dominant inheritance, or on the detection of an LDL receptor mutation $^{7}$ (found in $70 \%$ of the subjects).

The study was approved by the regional ethics committee, and informed consent was obtained. Bile acid binding resins were stopped two to six weeks before screening. Screening included a lipid profile and tests of liver and kidney function, dietary instructions, and clinical evaluation and was followed by a six week stabilisation phase. Subjects were then randomly allocated to colestipol, $10 \mathrm{~g}$ once daily or $5 \mathrm{~g}$ twice daily, or to matching placebo, for eight weeks in a double blind manner. Thereafter, those who had received placebo started colestipol $10 \mathrm{~g} /$ day for 52 weeks. Those who had received colestipol continued with the same dose for 44 additional weeks. Follow up visits were scheduled at randomisation, four and eight weeks thereafter, and after eight, 20, and 44 or 52 weeks in the open phase. Each visit included a blood test, review of the diet, and clinical evaluation. Compliance was assessed by the number of packets returned at each visit and the number of packets that were forgotten at home. Patients completed a questionnaire at the end of the randomised phase.

\section{DIETARY ASSESSMENT}

All the subjects were instructed to follow a diet containing $\leqslant 30 \%$ of energy from fat, $<10 \%$ of energy from saturated fat, and $<200 \mathrm{mg}$ cholesterol/d. Supplement users were defined as those who took cod liver oil or multivitainin supplements at least three times a week during six months or more of the year. Dietary intake was assessed at randomisation and after one year by a four day weighed food record, which included three weekdays and Saturday or Sunday.

\section{BLOOD ANALYSES}

Blood was drawn following a 10-12 hour fast. Serum cholesterol and triglycerides were 
determined by enzymatic methods. High density lipoprotein (HDL) cholesterol was measured after precipitation of apolipoprotein B containing lipoproteins with a standard heparin-manganese solution. LDL cholesterol was calculated by the Friedewald formula. ${ }^{8}$ Apolipoproteins A-I and B were measured by immunoturbidimetric methods. Serum carotenoids were analysed spectrophotometrically after extraction into $n$-heptane.

Serum samples for fat soluble vitamin analyses were stored at $-25^{\circ} \mathrm{C}$ and analysed 13 months after the end of the study. Vitamin levels were incomplete for seven subjects in the colestipol group and two subjects in the placebo group, and for three subjects who completed one year, because of insufficient serum. Serum vitamin A (retinol), 25-OH vitamin $\mathrm{D}$, and vitamin $\mathrm{E}$ ( $\alpha$-tocopherol) concentrations were determined by high performance liquid chromatography. ${ }^{9}$ Lower laboratory cutoff points were $0.7 \mu \mathrm{mol} / 1$ for vitamin $A, 30 \mathrm{nmol} / 1$ for vitamin $D$, and 14 $\mu \mathrm{mol} / \mathrm{l}$ for vitamin $\mathrm{E}$.

\section{STATISTICAL ANALYSES}

In the open phase, baseline lipid and nutrient values were concentrations at randomisation for those who received colestipol and concentrations following the randomised phase for those who received placebo. Continuous variables were compared using $t$ tests for paired or unpaired samples for normally distributed variables, and the Wilcoxon signed rank test or the Mann-Whitney test for skewed variables, as appropriate. Categorical variables were compared with the $\chi^{2}$ test. Change in height after one year was compared to Norwegian reference data. Two sided $\mathrm{p}$ values $<0.05$ were considered significant. For the assessment of changes in vitamin levels, $\mathrm{p}$ values $<0 \cdot 10$ were considered significant, to allow for a wider margin of safety.

\section{Results}

Baseline charactertistics were similar, other than age (table 1). Four subjects in the colestipol group and three in the placebo group dropped out before completing the randomised phase, because they refused to swallow the drug $(n=5)$ or because of unexpectedly low cholesterol concentrations at randomisation $(n=2)$. Eight girls

Table 1 Characteristics of children with familial hyperlipidaemia. Mean (SD) values or percentages are shown

\begin{tabular}{lcc}
\hline & $\begin{array}{c}\text { Colestipol } \\
(n=33)\end{array}$ & $\begin{array}{c}\text { Placebo } \\
(n=33)\end{array}$ \\
\hline Per cent males & 58 & 55 \\
Age in years & $12 \cdot 5(1 \cdot 5)$ & $13 \cdot 8(1 \cdot 6)^{\star}$ \\
Body mass index $\left(\mathrm{kg} / \mathrm{m}^{2}\right)$ & $19 \cdot 1(3 \cdot 3)$ & $20 \cdot 0(3 \cdot 1)$ \\
Tanner's pubertal stage & $2 \cdot 2(1 \cdot 3)$ & $3 \cdot 0(1 \cdot 5)^{\star}$ \\
Dietary intake & $23 \cdot 1(4 \cdot 2)$ & $23 \cdot 6(5 \cdot 2)$ \\
E\% total fat & $15 \cdot 8(3 \cdot 0)$ & $17 \cdot 1(3 \cdot 2)$ \\
E\% protein & $60 \cdot 5(5 \cdot 6)$ & $58 \cdot 9(5 \cdot 8)$ \\
E\% carbohydrates & $5 \cdot 0(1 \cdot 8)$ & $4 \cdot 9(1 \cdot 7)$ \\
E\% polyunsaturated fat & $7 \cdot 4(1 \cdot 9)$ & $7 \cdot 4(2 \cdot 1)$ \\
E\% saturated fat & $7 \cdot 9(2 \cdot 0)$ & $8 \cdot 1(2 \cdot 2)$ \\
E\% monounsaturated fat & $66(28)$ & $73(31)$ \\
Cholesterol mg/1000 kcal & & \\
\hline
\end{tabular}

${ }^{\star} \mathrm{p}<0.05 ;+\mathrm{E}=$ dietary energy. did not agree to continue in the open phase. Of the 51 remaining subjects, nine stopped the drug before the end of the study and 42 completed one year ( 31 boys and 11 girls).

\section{COMPLIANCE}

Mean compliance in the randomised phase was $68 \%$ in the colestipol group $v 76 \%$ in the placebo group (not significant). In the open phase, compliance was $79 \%$ in the first six months and $72 \%$ in the final six months.

\section{DIETARY CHARACTERISTICS}

Intake of major nutrients was similar in the colestipol and placebo groups (table 1), as was intake of vitamins (data not shown). Cod liver oil and multivitamins were taken by eight and one in the placebo group, and by seven and three in the colestipol group, respectively (not significant).

Twenty nine subjects completed the second dietary record. Dietary composition was similar to the initial record (data not shown). Of those who completed one year, 10 remained on a stable cod liver oil and/or multivitamin dose (including nine in the group who took $80 \%$ of the dose), four stopped taking the supplement (all in the group who took $<80 \%$ of the dose), and one (who took $80 \%$ of the dose) started a supplement.

\section{HEIGHT AND WEIGHT}

Linear growth velocity was within reference ranges for Norwegian adolescents. Only one participant lost $\geqslant 1 \mathrm{~kg}$ during the study, a boy whose initial and final body mass index values were $24.5 \mathrm{~kg} / \mathrm{m}^{2}$ and $21.3 \mathrm{~kg} / \mathrm{m}^{2}$, respectively.

\section{LIPID AND NUTRIENT LEVELS}

Total and LDL cholesterol and apolipoprotein B concentrations decreased by $14.0 \%, 19 \cdot 5 \%$, and $9.0 \%$, respectively, in the colestipol group versus $1.0 \%$ in the placebo group (table 2 ). Folate, vitamin E, and carotenoid concentrations decreased in the colestipol group. Apolipoprotein AI, calcium, phosphate, and ferritin concentrations did not differ between the two groups (data not shown).

After one year, total and LDL cholesterol concentrations remained decreased $(p=0.001$ and 0.0001 , respectively). The rise in triglycerides $(p=0.03)$ was associated with the increase in body mass index $(r=0.59$; $\mathrm{p}=0.0001)$. Vitamin $\mathrm{E} / \mathrm{ch}$ olesterol was increased $(p=0.0001)$. Folate concentrations remained decreased $(p=0.0005)$. Folate values were above the laboratory's lower reference point $(6.0 \mathrm{nmol} / \mathrm{l})$ in all subjects initially, but fell below it in two girls and one boy. Vitamin D concentrations decreased more in the group which took $\geqslant 80 \%$ of the dose than in the rest (table 3). Concentrations of vitamin $\mathrm{D}$ and vitamin $\mathrm{A}$ and the vitamin $\mathrm{E}$ to cholesterol ratio were above the cut off points for our laboratory and others ${ }^{10-12}$ in all subjects at the final visit. 
Table 2 Changes in levels of lipids, apolipoprotein B, and nutrients in the colestipol $(n=29)$ and placebo $(n=30)$ groups

\begin{tabular}{|c|c|c|c|c|}
\hline & $\begin{array}{l}\text { Colestipol } \\
\text { baseline }\end{array}$ & 8 Weeks & $\begin{array}{l}\text { Placebo } \\
\text { baseline }\end{array}$ & 8 Weeks \\
\hline $\begin{array}{l}\text { Lipids and apolipoprotein } B \\
\text { Total cholesterol }(\mathrm{mmol} / \mathrm{l}) \\
\text { Low density lipoprotein cholesterol }(\mathrm{mmol} / \mathrm{l}) \\
\text { High density lipoprotein cholesterol }(\mathrm{mmol} / \mathrm{l}) \\
\text { Triglycerides (mmol/) } \\
\text { Apolipoprotein B }(\mathrm{g} / \mathrm{l})\end{array}$ & $\begin{array}{l}8.16(1.47) \\
6.58(1.31) \\
1.12(0.25) \\
0.99(0.61) \\
1.26(0.23)\end{array}$ & $\begin{array}{l}6.99(1.46)^{\star} \\
5.27(1.29)^{\star} \\
1.19(0.35) \\
1.15(0.90) \\
1.15(0.26)^{\star}\end{array}$ & $\begin{array}{l}7 \cdot 69(1 \cdot 26) \\
6.13(1.18) \\
1 \cdot 12(0.20) \\
0.96(0.66) \\
1 \cdot 19(0.19)\end{array}$ & $\begin{array}{l}7.57(1.34) \\
6.01(1.32) \\
1.18(0.23) \\
0.84(0.36) \\
1.19(0.19)\end{array}$ \\
\hline $\begin{array}{l}\text { Nutrients } \\
\text { Erythrocyte folate }(\mathrm{nmol} / \mathrm{l}) \\
\text { Serum folate }(\mathrm{nmol} / 1) \\
\text { Vitamin A }(\mu \mathrm{mol} / 1) \\
\text { Vitamin } \mathrm{E}(\mu \mathrm{mol} / \mathrm{l}) \\
\text { Vitamin } \mathrm{E} / \mathrm{cholesterol} \\
25-\mathrm{OH} \text { vitamin } \mathrm{D}(\mathrm{nmol} / \mathrm{l}) \\
\text { Carotenoids }(\mu \mathrm{mol} / 1) \\
\text { Carotenoids/cholesterol }\end{array}$ & $\begin{array}{l}654(162) \\
15 \cdot 4(5 \cdot 3) \\
1 \cdot 7(0 \cdot 4) \\
25 \cdot 8(5 \cdot 7) \\
3 \cdot 1(0 \cdot 5) \\
58(18) \\
5 \cdot 0(1 \cdot 7) \\
0 \cdot 6(0 \cdot 2)\end{array}$ & $\begin{array}{l}648(196) \\
13 \cdot 8(5 \cdot 7)^{\star} \\
1 \cdot 9(0 \cdot 5) \\
21 \cdot 0(7 \cdot 1)^{\star} \\
3 \cdot 1(0 \cdot 8) \\
53(18) \\
4 \cdot 2(1 \cdot 4)^{\star} \\
0 \cdot 6(0 \cdot 2)^{\star}\end{array}$ & $\begin{array}{l}561(141) \\
13.9(4 \cdot 5) \\
1.7(0 \cdot 4) \\
22.9(5 \cdot 7) \\
3.0(0 \cdot 4) \\
56(16) \\
4.9(1 \cdot 6) \\
0.6(0 \cdot 2)\end{array}$ & $\begin{array}{l}584(143) \\
16 \cdot 4(6 \cdot 7) \\
1 \cdot 8(0 \cdot 4) \\
22 \cdot 8(3 \cdot 9) \\
3 \cdot 1(0 \cdot 5) \\
56(24) \\
5 \cdot 8(2 \cdot 2) \\
0 \cdot 8(0 \cdot 3)\end{array}$ \\
\hline
\end{tabular}

${ }^{\star} \mathrm{p} \leqslant 0.01$ compared with placebo.

\section{SIDE EFFECTS}

Eight subjects taking colestipol had gastrointestinal side effects attributed to the drug. Two had constipation that improved with temporary dose reduction. One had dyspepsia and one had flatulence throughout the study, two had intermittent nausea, one had a temporary reduction in appetite, and one had abdominal pain which improved on dose reduction.

\section{SUBJECTIVE EVALUATIONS}

Only $21 \%$ liked the taste of the colestipol/fluid mixture, $44 \%$ did not take the drug on holidays, special occasions, or trips, and $37 \%$ frequently forgot to take it. Of 21 subjects who had taken a resin previously, $86 \%$ preferred the new formulation of colestipol.

\section{Discussion}

We found that low dose colestipol (10 g/day) reduced concentrations of serum folate after eight weeks. Serum vitamin $\mathrm{E}$ and carotenoids were lowered, but the decrease was proportionate to the decrease in cholesterol. Vitamin D concentrations did not change significantly during the eight week randomised phase, but after one year they decreased more in subjects who were compliant than in the rest.

In previous studies, treatment effects on serum folate have varied. ${ }^{13-17}$ We are not aware of previous placebo controlled studies. Decreases in erythrocyte folate levels have also been noted, ${ }^{14}$ leading to the suggestion that folate supplementation should be given, ${ }^{13}$ though this is not recommended in the official Norwegian drug manual. ${ }^{18}$ Erythrocyte folate concentrations did not fall in our study, possibly because of the lower dose of colestipol used in comparison with the earlier study. ${ }^{14}$ While a decrease in serum folate alone may not represent a significant deficiency, low serum folate has been associated with raised total homocysteine, a risk factor for cardiovascular disease. ${ }^{19}$ Thus we consider folate supplementation to be prudent, especially as the values in three subjects fell from within to below the normal range. As the one year findings were not controlled, it remains possible that the decrease in folate was attributable to sexual maturation. ${ }^{20}$

Product specifications indicate that resins may cause malabsorption of fat soluble vitamins. ${ }^{18}$ Tsang et al observed a decrease in $25-\mathrm{OH}$ vitamin $\mathrm{D}$ levels after 20 months of colestipol. ${ }^{21}$ In a subsequent study, vitamin D levels were unchanged in five children who took colestipol for two years. ${ }^{16}$ Our findings of a fall in vitamin $\mathrm{D}$ concentrations in the compliant group may be due to chance. However, use of vitamin supplements was more frequent in this group and may have masked a greater drop. The randomised eight week phase was probably too short for vitamin $\mathrm{D}$ depots to diminish.

Glueck et al reported that vitamin E concentrations in children taking resins were similar to controls and did not decrease during treatment, ${ }^{22} 23$ while Schwarz et al observed a decline. ${ }^{16}$ Neither study reported changes in the vitamin $\mathrm{E}$ to lipid ratios. In the present

Table 3 Lipids and nutrients after one year of colestipol in adolescents who took $\geqslant 80 \%$ of the dose or $<80 \%$

\begin{tabular}{|c|c|c|c|c|}
\hline & \multicolumn{2}{|c|}{ Took $\geqslant 80 \%(n=21)$} & \multicolumn{2}{|c|}{ Took $<80 \%(n=21)$} \\
\hline & Baseline & 1 Year & Baseline & 1 Year \\
\hline $\begin{array}{l}\text { Lipids } \\
\text { Total cholesterol (mmol/1) } \\
\text { Low density lipoprotein cholesterol (mmol//) } \\
\text { High density lipoprotein cholesterol (mmol/1) } \\
\text { Triglycerides (mmol/ })\end{array}$ & $\begin{array}{l}7 \cdot 33(1 \cdot 37) \\
5 \cdot 80(1 \cdot 44) \\
1 \cdot 20(0 \cdot 26) \\
0 \cdot 71(0 \cdot 28)\end{array}$ & $\begin{array}{l}6.69(0.97) \\
5.07(1.04) \\
1 \cdot 20(0.30) \\
0.92(0.47)\end{array}$ & $\begin{array}{l}8 \cdot 11(1 \cdot 39) \\
6 \cdot 50(1 \cdot 19) \\
1 \cdot 10(0 \cdot 23) \\
1 \cdot 10(0 \cdot 69)\end{array}$ & $\begin{array}{l}7 \cdot 67(1.35) \\
5.96(1.19) \\
1 \cdot 12(0.22) \\
1.28(0.72)\end{array}$ \\
\hline $\begin{array}{l}\text { Nutrients } \\
\text { Erythrocyte folate }(\mathrm{nmol} / \mathrm{l}) \\
\text { Serum folate }(\mathrm{nmol} / \mathrm{l}) \\
\text { Vitamin A }(\mu \mathrm{mol} / 1) \\
\text { Vitamin E }(\mu \mathrm{mol} / 1) \\
\text { Vitamin E/cholesterol } \\
25-O H \text { vitamin D }(\mathrm{nmol} / \mathrm{l}) \\
\text { Carotenoids }(\mu \mathrm{mol} / 1) \\
\text { Carotenoids/cholesterol }\end{array}$ & $\begin{array}{l}647(151) \\
17 \cdot 6(7 \cdot 1) \\
1 \cdot 8(0 \cdot 4) \\
23 \cdot 2(5 \cdot 6) \\
3 \cdot 2(0 \cdot 7) \\
61(27) \\
5 \cdot 8(1 \cdot 7) \\
0 \cdot 8(0 \cdot 3)\end{array}$ & $\begin{array}{l}650(304) \\
13 \cdot 7(6 \cdot 0) \\
1 \cdot 9(0 \cdot 5) \\
25 \cdot 9(4 \cdot 9) \\
3 \cdot 9(0 \cdot 5) \\
50(17)^{\star} \\
4 \cdot 6(1 \cdot 8) \\
0 \cdot 7(0 \cdot 3)\end{array}$ & $\begin{array}{l}634(157) \\
15 \cdot 2(5 \cdot 7) \\
1 \cdot 8(0 \cdot 4) \\
24 \cdot 1(4 \cdot 4) \\
3 \cdot 0(0 \cdot 3) \\
56(15) \\
4 \cdot 7(1 \cdot 2) \\
0 \cdot 6(0 \cdot 2)\end{array}$ & $\begin{array}{l}599(208) \\
11.8(5 \cdot 2) \\
1.7(0 \cdot 6) \\
25 \cdot 5(4 \cdot 2) \\
3.4(0 \cdot 5) \\
54(17) \\
4 \cdot 0(0 \cdot 9) \\
0.5(0 \cdot 1)\end{array}$ \\
\hline
\end{tabular}


study, the vitamin $\mathrm{E}$ to cholesterol ratio, which is sensitive and specific for vitamin $\mathrm{E}$ deficiency, ${ }^{12}$ was unchanged in the randomised phase, though absolute levels fell. The ratio increased after one year. Both low absolute levels and low vitamin $\mathrm{E}$ to lipid ratios have been associated with cardiovascular risk. ${ }^{24} 25$

In contrast to Smith et al, ${ }^{26}$ but in accordance with the National Heart, Lung and Blood Institute five year study of cholestyramine,${ }^{27}$ our data indicate that vitamin A levels are not lowered by resins, despite a decline in levels of carotene in both our own and the Institute studies. The Institute study did not report changes in carotene to lipid ratios, and these did not fall in our study.

Low dose colestipol lowered LDL cholesterol levels by almost $20 \%$ during the randomised phase of our study. Higher doses of colestipol cause proportionately smaller decreases in lipid levels. ${ }^{28}$ Thus we recommend a low dose for children and adolescents, rather than the doses used 15-20 years ago. ${ }^{13-16}$ HDL cholesterol concentrations did not increase, in contrast to findings in an uncontrolled report. ${ }^{5}$ Though several adolescents reported gastrointestinal symptoms that were likely to be due to the drug, none required discontinuation of colestipol, confirming earlier findings that resins are well tolerated in youth. ${ }^{5623}$ Resins do not appear to have an adverse effect on growth. ${ }^{31429}$ However, early satiety or nausea may limit food intake and weight gain. These side effects were few and temporary in our patients.

Only one third of the adolescents adhered to the drug regimen in the course of one year. Obstacles to taking the drug included vacations, special occasions, and unpalatability. However, most of those who had taken a resin previously preferred the orange flavoured formulation.

In conclusion, during treatment with low dose colestipol, folate and probably vitamin $\mathrm{D}$ supplementation is advisable. The main obstacle to successful lipid lowering treatment appears to be the unpalatability of bile acid binding resins, rather than side effects.

We thank Jørgen Knudtzon of the Department of Paediatrics, National Hospital, Oslo, for the comparison of growth data with national standards and Trond $\mathrm{P}$ Leren of the Department of Medical Genetics, Ulleval hospital, Oslo, for the DNA analyses. We thank Stein Evensen of the Medical Department A, We thank Stein Evensen of the Medical Department A,
National Hospital, Oslo, for his suggestions. Financial support was given by the Upjohn Company.

1 National Cholesterol Education Program. Report of the expert panel on blood cholesterol levels in children and adolescents. Pediatrics 1992; 89 (suppl): 525-84.

adolescents. Pediatrics $1992 ; 89$ (suppl): $525-84$.
2 International Task Force for Prevention of Coronary Heart Disease. Prevention of coronary heart disease: scientific background and new clinical guidelines. Nutr Metab Cardiovasc Dis 1992; 2: 113-56.
3 Stein EA. Drug therapy in children and adolescents with familial hypercholesterolemia. Recent aspects of diagnosis and treatment of lipoprotein disorders: impact on prevention of atherosclerotic diseases. New York: Alan R Liss, 1988: 273-80.

4 West RJ, Lloyd JK. Long-term follow-up of children with familial hypercholesterolaemia treated with cholestyramine. Lancet 1980; ii: 873-5.

5 Schlierf G, Mrozik K, Heuck CC, et al. 'Low dose' colestipol in children, adolescents and young adults with familial hypercholesterolaemia. Atherosclerosis 1982; 41: 133-8.

6 Liacouras CA, Coates PM, Gallagher PR, et al. Use of cholestyramine in the treatment of children with familial of cholestyramine in the treatment of children with familial

7 Leren TP, Solberg K, Rødningen OK, et al. Two founder Leren TP, Solberg K, Rødningen OK, et al. Two founder
mutations in the LDL receptor gene in Norwegian familial hypercholesterolemia subjects. Atherosclerosis 1994; 111 175-82.

8 Friedewald WT, Levy RI, Fredrickson DS. Estimation of the concentration of low density lipoprotein cholesterol without the use of the preparative ultracentrifuge. Clin Chem 1972; 18: 499-502

9 Aksnes L. Simultaneous determination of retinol, alphatocopherol and 25-hydroxyvitamin D in human serum by high-performance liquid chromatography. $\mathcal{f}$ Pediat Gastroenterol Nutr 1994; 18: 339-43.

10 Holick MF. The use and interpretation of assays for vitamin $\mathrm{D}$ and its metabolites. $\mathcal{F}$ Nutr 1990; 120: 1464-9.

11 Underwood BA. Methods for assessment of vitamin A status. F Nutr 1990; 120: 1459-63.

12 Thurnham DI, Davies JA, Crump BJ, et al. The use of different lipids to express serum tocopherol : lipid ratios for the measurement of vitamin E status. Ann Clin Biochem 1986; 23: 514-20.

13 West RJ, Lloyd JK. The effect of cholestyramine on intestinal absorption. Gut 1975; 16: 93-8.

14 West RJ, Lloyd JK. Use of cholestyramine in treatment of children with familial hypercholesterolaemia. Arch Dis Child 1973; 48: 370-4

15 Farah JR, Kwiterovich PO, Neill CA. Dose-effect relation of cholestyramine in children and young adults with familial hypercholesterolaemia. Lancet 1977; i: 59-63.

16 Schwarz KB, Goldstein PD, Witztum JL, et al. Fat-soluble vitamin concentrations in hypercholesterolemic children treated with colestipol. Pediatrics 1980; 65: 243-50.

17 Schlierf G, Vogel G, Kohlmeier M, et al. Long term treatment of young patients with familial hypercholesterolemia with colestipol: plasma levels of minerals and vitamins. With Colestipol: plasma levels of

18 Norwegian Pharmaceutical Products Compendium 1995/96; 37: 673-4.

19 Stampfer MJ, Malinow MR, Willett WC, et al. A prospective study of plasma homocyst(e)ine and risk of myocardial infarction in US physicians. $\mathscr{J} A M A 1992 ; 268$ : 877-81

20 Bailey LB. Folate status assessment. I Nutr 1990; 120: 1508-11.

21 Tsang RC, Roginsky MS, Mellies MJ, et al. Plasma 25hydroxy-vitamin $\mathrm{D}$ in familial hypercholesterolemic children receiving colestipol resin. Pediatr Res 1978; 12: 980-2.

22 Glueck CJ, Tsang RC, Fallat RW, et al. Plasma vitamin A and $\mathrm{E}$ levels in children with familial type II hyperlipoproteinemia during therapy with diet and cholestyramine teinemia during therapy with
resin. Pediatrics $1974 ; 54: 51-5$.

23 Glueck CJ, Fallat RW, Mellies M, et al. Pediatric familial type II hyperlipoproteinaemia therapy with diet and type II hyperlipoproteinaemia therapy with
colestipol resin. Pediatrics 1976; 57: 68-74.

24 Gey KF, Puska P, Jordan P, et al. Inverse correlation between plasma vitamin $\mathrm{E}$ and mortality from ischemic heart disease in cross-cultural epidemiology. Am $\mathrm{f}$ Clin Nutr 1991; 53 (suppl): 326-34.

25 Riemersma RA, Wood DA, Macintyre CCA, et al. Risk of angina pectoris and plasma concentrations of vitamins $A$, $\mathrm{C}$, and $\mathrm{E}$ and carotene. Lancet 1991; 337: 1-5.

26 Smith DK, Greene JM, Leonard SB, et al. Vitamin A in hypercholesterolemia. Am $\mathcal{F}$ Med Sci 1992; 304: 20-4.

27 Bresnike JF, Levy RI, Kelsey SF, et al. Effects of therapy with cholestyramine on progression of coronary arteriosclerosis: results of the NHLBI Type II Coronary Intervention Study. Circulation 1984; 69: 313-24.

28 Superko HR, Greenland P, Manchester RA, et al. Effectiveness of low-dose colestipol therapy in patients with moderate hypercholesterolemia. Am f Cardiol 1992; w0: $135-40$.

29 Hansen D, Michaelsen KF, Skovby F. Growth during treatment of familial hypercholesterolemia. Acta Paediatr Scand 1992; 81: 1023-5. 